\title{
Severe Tricuspid Valve Stenosis
}

\section{A Cause of Silent Mitral Stenosis}

\author{
Abdolhamid Sheikhzadeh, M.D., Homayoon Moghbeli, M.D., \\ Parviz Ghabussi, M.D., and Siavosh Tarbiat, M.D.
}

\section{Summary}

The diastolic rumbling murmur of mitral stenosis (MS) may be attenuated in the presence of low cardiac output, right ventricular enlargement, Lutembacher's syndrome, pulmonary emphysema, and obesity. In this report we would like to stress that the presence of tricuspid stenosis (TS) is an additional significant cause of silent MS.

The clinical material consisted of 73 patients with rheumatic TS who had undergone cardiac surgery. Five of these cases had clinical findings of TS without auscultatory findings of MS. They were found to have severe MS at the time of operation and to require mitral valve surgery. At cardiac catheterization the mean diastolic gradient (MDG) across the mitral valve (MV) was less than $3 \mathrm{mmHg}$ and pulmonary arterial systolic pressure was 29$42 \mathrm{mmHg}$. The MDG across the tricuspid valve was 6-17 $\mathrm{mmHg}$.

In conclusion, TS can mask clinical and hemodynamic findings of MS. The reason for this is the mechanical barrier imposed by TS proximal to the MV.

\section{Additional Indexing Words:}

Rheumatic valvular disease Atrial imprint Tricuspid valve surgery

ThE most common silent valvular lesion is that of mitral stenosis (MS). ${ }^{11}$
The auscultatory findings of MS particularly the diastolic rumble, can be masked in patients with low cardiac output, ${ }^{2}$ severe pulmonary hypertension right ventricular hypertrophy, ${ }^{3)}$ Lutembacher's syndrome, ${ }^{4)}$ pulmonary emphysema, and obesity. ${ }^{2)}$ The purpose of this communication is to report another cause of true silent MS. In this report we present evidence that

From the Departments of Adult Cardiology, Cardiovascular Surgery, Cardiovascular Medical and Research Centre (Heart Hospital), Teheran, Iran.

Address for reprint: A. Sheikhzadeh, M.D., Cardiovascular Medical and Research Centre, P.O. Box 33-324, Shemiran, Teheran, Iran.

Received for publication October $27,1981$.

Manuscript revisedJune 22, 1982. 
tricuspid stenosis (TS) masks auscultatory and even hemodynamic findings of MS.

\section{Materials ANd Methods}

Among 936 patients with rheumatic valvular disease seen during a period of 70 months, 73 patients with TS underwent open heart surgery and were followed for a mean of 38 months. Preoperatively, all patients had a complete physical examination with particular attention to the jugular venous pressure curve, hepatic pulsation and precordial auscultation. A 12-lead electrocardiogram and chest roentgenogram were obtained on all patients. A phonocardiogram was recorded on a 12-channel $\mathrm{E}$ for $\mathrm{M}$ and 6-channel Phillips (Honeywell) U.V. recorder at paper speed of 50 and $100 \mathrm{~mm} / \mathrm{sec}$. The recording were usually obtained during the expiratory phase. Complete right and left heart catheterization were performed on all patients in a fasting state and without premedication. Simultaneous pressures were recorded from the right ventricle and right atrium using 2 end hole venous catheters, one positioned in the right ventricular cavity and the other in the right atrial cavity. The pressures were recorded using equisensitive transducers (Model P 23 Statham), with the recordings taken from the same baseline. The cardiac output was measured by the Fick method and mitral and mitral and tricuspid valve areas were calculated hemodynamically using Gorlin's formula.5) To ensure optimal auscultation of the mitral diastolic rumble and other auscultatory findings of MS, all patients were examined in the left lateral position after the point of maximal impulse of the left ventricle was located and held by the palpating finger. The bell of the stethoscope was then lightly placed over this localized area, barely making an air seal. ${ }^{1)}$ All patients were examined by at least 2 independent investigators. Follow up studies were performed on all patients, 52 patients had complete hemodynamic studies postoperatively, while 21 patients refused postoperative hemodynamic studies. Phonocardiogram was recorded in 3 of these 5 with silent MS cases with particular attention to the area over the point of maximum impulse and the fifth left parasternal intercostal space to record the diastolic rumble and opening snap of MS and TS, respectively.

\section{RESULTS}

Of the 73 patients with TS, 30 were male, and 43 female. These patients represented $6 \%$ of the total number of patients with rheumatic heart disease who underwent open heart surgery during the same period of time in 


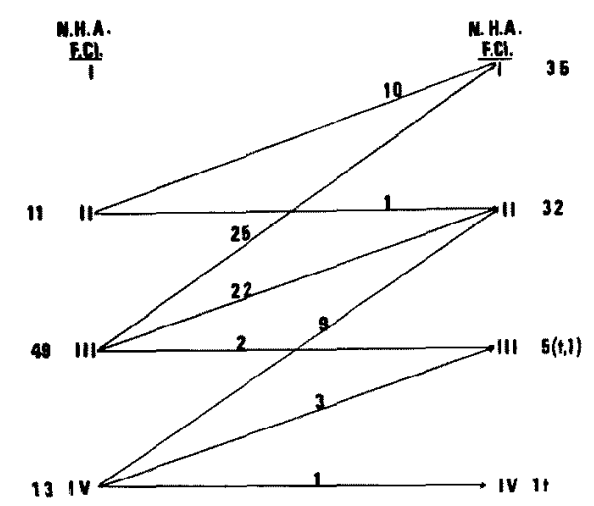

Fig. 1. New York Heart Association classification of 73 cases with chronic rheumatic tricuspid stenosis before and after open heart surgery.

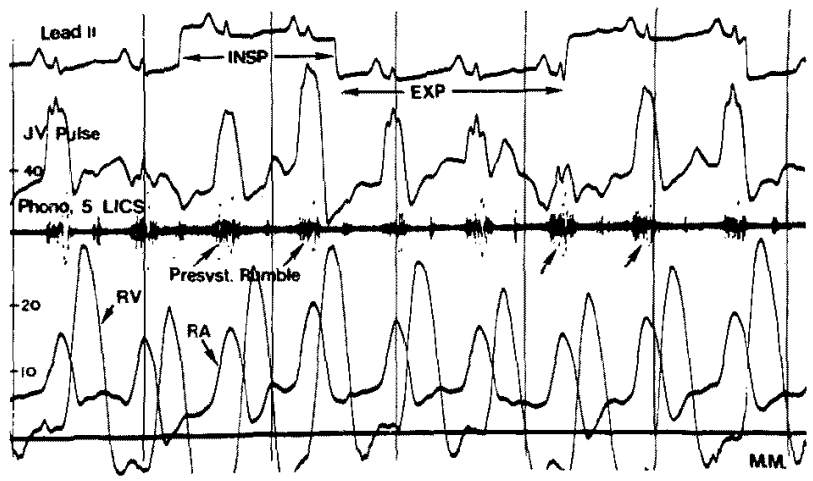

Fig. 2. Simultaneous recording of right atrial pressure (RA), right ventricular pressure (RV), electrocardiogram, jugular venous (JV) pulse, and phonocardiogram over the left fffth inter-costal space para sternally (LICS). Note the increasing of the tricuspid valve gradient and the accentuation of the presystolic rumble.

this center. Their ages ranged between 12 to 48 years with the mean of $29 \pm$ 11.2 years. The most common combined valvular lesion was TS and MS followed by TS and MS associated with tricuspid regurgitation. In 1 patient all four valves were involved. The majority of patients were clinically in NYHA functional class III and IV (Fig. 1).

While 68 patients had auscultatory findings of combined valvular lesions which were proven at surgery, 5 others had auscultatory findings of only pure TS. In these 5 patients there was no auscultatory evidence for MS using the above described method of auscultation. In 1 case mitral opening snap was suggested by one of the investigators. However, even repeated auscultation after cardiac catheterization and left ventricular angiography in these 5 cases, 
Table I. Auscultatory and Phonocardiographic Features in 73 Patients with Rheumatic Tricuspid Stenosis

\begin{tabular}{l|c|c}
\hline & Number of patients & $\%$ \\
\hline Tricuspid mid-diastolic murmur & $68 / 73$ & 93 \\
Tricuspid regurgitant murmur & $12 / 73$ & 16.4 \\
Tricuspid presystolic murmur & $35 / 73$ & 48 \\
Tricuspid opening snap & $48 / 73$ & 65.7 \\
Large jugular "A" waves & $42 / 73$ & 57.5
\end{tabular}

Table II. Auscultatory and Phonocardiographic Findings in 5 Patients with Rheumatic Tricuspid Stenosis and Silent Mitral Stenosis

\begin{tabular}{l|c|c}
\hline & Number of patients & $\%$ \\
\hline Tricuspid mid-diastolic murmur & $5 / 5$ & 100 \\
Tricuspid regurgitant murmur & $0 / 5$ & - \\
Tricuspid presystolic murmur & $4 / 5$ & 80 \\
Tricuspid opening snap & $0 / 5$ & - \\
Large jugular "A" waves & $4 / 5$ & 80
\end{tabular}

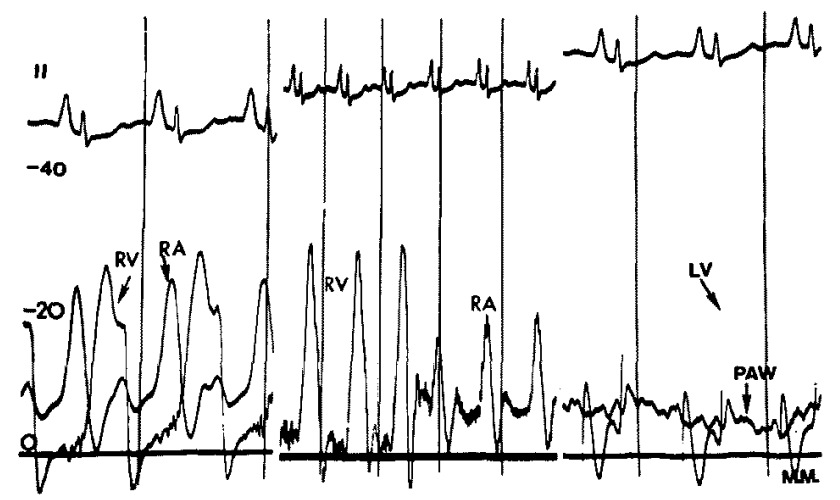

Fig. 3. Right atrial (RA), right ventricular (RV), left ventricular $(\mathrm{LV})$, and pulmonary artery pressure curves in Case 1. Note the severc tricuspid valve gradient and the absence of a mitral valve gradient (scale 20$40 \mathrm{mmHg}$ ).

confirmed true silent MS.

A mid-diastolic murmur was audible in the fifth left intercostal space parasternally in all 5 cases, and a presystolic murmur in 4 cases. All auscultatory findings in all patients were accentuated on inspiration. The phonocardiogram which was done in 3 of these 5 cases failed to record a mitral diastolic rumble or a mitral opening snap over the point of maximum impulse. In all 3 cases a mid-diastolic rumble and presystolic murmur were recorded in the fifth left parasternal intercostal space simultaneously with RA 
Table III. Hemodynamic Findings in 5 Cases of Chronic Rheumatic Tricuspid Stenosis with Silent Mitral Stenosis

\begin{tabular}{|c|c|c|c|c|c|}
\hline Age and sex & $\underset{17 \mathrm{~F}}{\text { Case }} 1$ & $\begin{array}{c}\text { Case } 2 \\
22 \mathrm{M}\end{array}$ & $\underset{27 \mathrm{~F}}{\text { Case }} 3$ & $\begin{array}{c}\text { Case }{ }^{4} \\
21 \mathrm{M}\end{array}$ & $\begin{array}{c}\text { Case } 5 \\
18 \mathrm{~F}\end{array}$ \\
\hline Site & $a=25$ & $\mathrm{a}=22$ & $a=28$ & $a=20$ & $\mathrm{cv}=26$ \\
\hline & $\mathbf{x}=0$ & $x=2$ & $x=16$ & $x=3$ & $y=20$ \\
\hline RA $\mathrm{mmHg}$ & $v=10.5$ & $\mathrm{v}=18$ & $v=29$ & $v=7$ & $(22)$ \\
\hline & $y=8$ & $\begin{array}{c}y=8 \\
(15)\end{array}$ & $\begin{array}{c}y=24 \\
(24)\end{array}$ & $\begin{array}{c}y=8 \\
(13)\end{array}$ & \\
\hline $\mathrm{RV} \mathrm{mmHg}$ & $29 / 3$ & $35 / 0-6$ & $36 / 0-7$ & $26 / 0-2$ & $42 / 12$ \\
\hline PA $\mathrm{mmHg}$ & $\begin{array}{c}29 / 15 \\
(19)\end{array}$ & $35 / 18$ & $36 / 17$ & $26 / 18$ & $\begin{array}{c}42 / 24 \\
(30)\end{array}$ \\
\hline PAW mmHg & (5) & $(6.5)$ & (8) & $(10)$ & $(27)$ \\
\hline $\mathrm{LV} \mathrm{mmHg}$ & $110 /-4$ & $130 /-6$ & $110 /-6.5$ & $140 / 0-8$ & $120 / 24$ \\
\hline Ao & $110 / 68$ & $130 / 70$ & $110 / 70$ & $140 / 70$ & $120 / 72$ \\
\hline
\end{tabular}

$\mathrm{F}=$ female $; \quad \mathrm{M}=$ male $; \quad \mathrm{RA}=$ right atrium; $\mathrm{RV}=$ right ventricle; $\mathrm{PA}=$ pulmonary artery ; PAW = pulmonary artery wedge $; \mathrm{LV}=$ left ventricle; Ao=aorta.

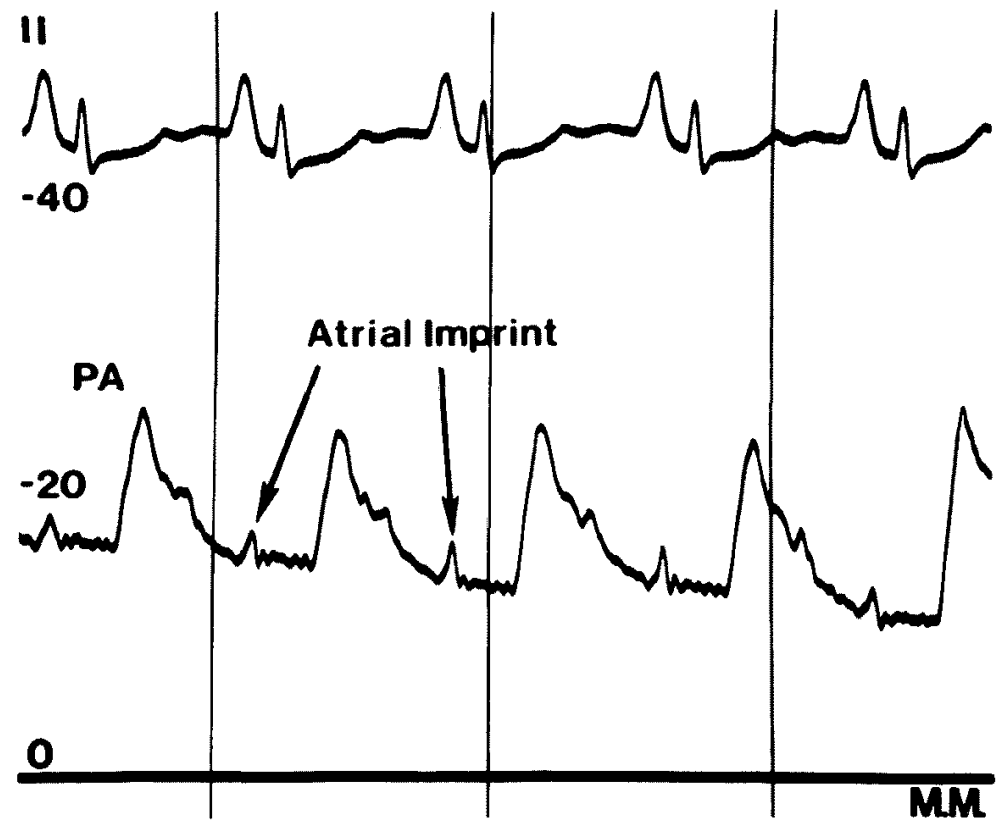

Fig. 4. Atrial imprint in Case 1.

and RV pressure (Fig. 2). The right atrioventricular diastolic and right atrial presystolic murmurs both increased during inspiration (Carvallo's sign) corresponding to augmented venous return and increased gradient and flow across the stenotic tricuspid valve during that phase of the respiratory cycle (Fig. 2). The auscultatory findings for TS are summarized in Table I, and 
for the 5 patients with TS and silent MS in Table II. Four of these 5 cases had normal sinus rhythm and 1 had atrial fibrillation. The $\mathbf{P}$ waves in lead II were 5-8 $\mathrm{mm}$. Three cases had right ventricular hypertrophy. All cases underwent open heart surgery.

The preoperative hemodynamic data from the 5 cases with silent MS are shown in Table III. While there were significant pressure gradients across $\mathrm{TV}$ in all 5 cases of severe TS combined with silent MS, no hemodynamically significant gradients were detected across $\mathrm{MV}$ (less than $3 \mathrm{mmHg}$ in all cases) (Fig. 3, Table III). Three of the 4 cases of TS with silent MS and sinus rhythm had an atrial imprint in the pulmonary artery pressure curve (Fig. 4). Of the rest of the 73 patients with TS only 2 patients had an atrial imprint. These 2 cases also had low pulmonary artery pressure (mean PAP $26 \mathrm{mmHg}$ and $29 \mathrm{mmHg}$, respectively). There was a good correlation between the timing of the $\mathrm{P}$ waves in the electrocardiogram and the atrial imprint of the pulmonary artery curve in all cases. All 5 cases had gross evidence of severe MS at surgery requiring surgical manipulation of MV in addition to surgical correction of TS. Three patients required tricuspid valve commissurotomy and or repair. Two patients needed tricuspid valve replacement.

\section{Discussion}

Tricuspid stenosis, like MS, is almost always of rheumatic origin and occurs more frequently than has been previously recognized. ${ }^{61,7)}$ Silent mitral stenosis is the most common silent valvular disease, although true silent mitral stenosis is not a common lesion. ${ }^{1)}$ The graphic documentation of silent valvular disease specially in the presence of other concomitant valvular involvement is difficult. Most papers dealing with this problem are based on careful auscultation. ${ }^{1)}$ In somc conditions such as obcsity and severe pulmonary emphyscma, a faint diastolic rumble may be masked. Severe right atrial (RA) and right ventricular (RV) hypertrophy and or enlargement may change the position of $\mathrm{MV}$, thereby making the diastolic rumble in audible. In Lutembacher's syndrome, or low cardiac output, the silent MS is most probably due to the hemodynamic condition leading to diminished flow through the stenotic MV. 2),4) The masking of hemodynamic features of MS by severe TS is well documentated in our study. The absence of a hemodynamically significant pressure gradient across the mitral valve in the presence of severe TS as we have shown, may explain the absence of auscultatory evidence of MS, or so called "silent mitral stenosis". We believe that severe stenotic tricuspid valve (TV) is a mechanical barrier, causing reduced right ventricular stroke volume and pulmonary flow, and eventually decreasing mitral valvular 
flow which in turn causes a very low or nonexistant gradient across MV. This finding confirms the early postulation of Bayer, Loogen et al.9)

Another interesting finding was the presence of an atrial imprint in the pulmonary artery pressure curve. This finding was present in patients with relatively low pulmonary artery and right ventricular pressure. Forceful contraction of the right atrium with elevated pressure due to TS in the presence of relatively low pressure in the pulmonary artery and right ventricle may be the cause of this atrial imprint in the pulmonary artery pressure curve. This can also be explained by the presence of a mechanical barrier at the level of the TV. We believe that the contraction of the right atrium is transmitted directly to the pulmonary artery because of the presence of TS and concomitant low pulmonary artery pressure. The correlation of the timing of the $\mathbf{P}$ wave in the electrocardiogram and the atrial imprint in the pulmonary artery pressure curve is good evidence for this assumtion.

In conclusion, we have demonstrated that severe TS cannot only mask the auscultatory findings of MS but that the hemodynamic findings of MS can also be markedly altered. Thus, we suggest that in the presence of severe TS, classic auscultatory and hemodynamic findings of a significant associated MS might be absent, so-called "silent MS". In these circumstances other methods of diagnosis besides cardiac catheterization, particularly echocardiogram of the mitral valve are mandatory to ensure an accurate preoperative diagnosis. Moreover, surgical exploration of the MV is advisable in such cases. The atrial imprint in the pulmonary artery pressure curve in cases of TS with low pulmonary artery pressure and specially in TS with silent MS, is not uncommon.

\section{AcKnowledgment}

We wish to thank Dr. R. Masumi for the illustration of Case 1 and Mrs. Nadereh Hobbi and Mrs. Ch. Meißner for their secreterial assistance.

\section{REFERENGES}

1. Harvey WP: Silent valvular heart disease. in Valvular Heart Disease. Cardiovascular Clinics, ed by Likoff W, Brest AN, FA Davis Co, Philadelphia, p 78, 1973

2. Braunwald E: Heart Disease. Valvular Heart Disease, WB Saunders Co, Philadelphia, London, Toronto, p 1 101, 1980

3. Likoff W, Segal BL, Kasper AJ, Kasparian H, Novack P: Silent rheumatic valvular disease. Dis Chest 49: 362, 1966

4. EL-Sharif N, EL-Mallah S: The acquired Lutembacher's syndrome: a cause of silent mitral stenosis. J Egyp Med Assoc 51 : 723, 1968

5. Gorlin R, Gorlin S: Hydraulic formula for calculation of the area of the stenotic mitral valve, other valves and central circulatory shunts. Am Heart J 41: 1, 1951 
6. Kitchen A, Turner R: Diagnosis and treatment of tricuspid stenosis. Br Heart J 26: 354, 1969

7. Baily CP, Bolten HF: Criteria for and results of surgery for mitral stenosis. NY State J Med 56: 649,1959

8. Sheikhzadeh A, Tarbiat S, Paydar D, Shakibi J: Rheumatic tricuspid stenosis. A clinical overview. Acta Cardiologica 33: 431, 1978

9. Bayer O, Loogen F, Wolter HH, Grosse-Brockhoff F: Die Herzkatheterisierung bei angeborenen und erworbenen Herzfehlern. Georg Thieme Verlag, Stuttgart, p 266, 1976 